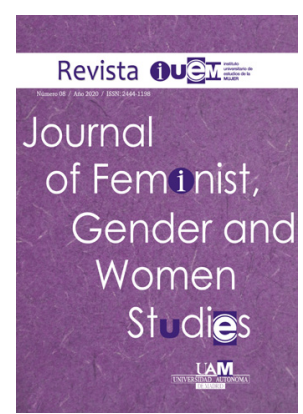

Recibido: $21 / 01 / 2020$

Aceptado: 19/05/2020

\section{Movimientos reivindicativos de las mujeres en Roma durante el s. II a.C.: el caso de la derogación de la Ley Opia}

\author{
Vindictive movements of women in Rome during the second century b.C.: the case \\ of the repeal of the Lex Oppia
}

\author{
Alejandra Sentís Vicent ${ }^{1, @}$ \\ ${ }^{1}$ Universidad Autónoma de Madrid. \\ @ Autor/a de correspondencia: alejandra.sentis@alumni.uam.es
}

\begin{abstract}
Resumen
Esta investigación se propone aplicar los estudios de género a la historia antigua, con el objetivo de mostrar la existencia de movimientos sociales reivindicativos protagonizados por las mujeres en la antigua Roma. La hipótesis que sustenta este trabajo es que las mujeres comenzaron a ocupar el ámbito público y a protagonizar reivindicaciones muchos siglos antes de la aparición del feminismo a finales del s. XVIII. Debido a la amplitud del ámbito de estudio considerado, este artículo se limita a la época republicana, específicamente en el siglo II a.C. Por ello, se ha decidido analizar un caso concreto: la manifestación de las matronas romanas para la derogación de la ley Opia (195 a.C.). La metodología de la investigación ha consistido en la lectura crítica y el análisis con perspectiva de género de las fuentes clásicas junto con una revisión de la bibliografía moderna. La ley Opia impuso severas restricciones en los bienes y libertades de las mujeres romanas de la élite, lo que provocó que veinte años después de su promulgación tuviera lugar un movimiento organizado liderado por ellas, que obtuvo el apoyo de buena parte de su grupo social. Mientras estas matronas salían a las calles de Roma de forma multitudinaria, en el foro tuvo lugar un debate entre Catón, representando a la facción conservadora de la sociedad en contra de la derogación de la ley Opia, y Valerio, tribuno de la plebe, que estaba a favor de dicha derogación.
\end{abstract}

Palabras clave: ley Opia, matronas romanas, reivindicaciones femeninas, estudios de género, Antigüedad, feminismo.

\begin{abstract}
This research aims to apply gender studies to ancient history, with the purpose of showing the existence of social movements led by women in ancient Rome. The hypothesis that supports this work is that women began to be more present in the public sphere and raised feminist demands many centuries before the emergence of feminism in the late 18th century. Due to the magnitude of the idea of this study, the current essay only focusses on the Republican period and most specifically on the 2 nd century B.C. The event analysed in this essay is the demonstration of the Roman matrons in order to repeal the lex Oppia (195 B.C.) The research methodology was based on a critical reading of classical sources with gender perspective, along with a review of a more modern literature. The lex Oppia imposed severe restrictions on the wealth and freedom for upper class Roman women. The implementation of this law led to the emergence of an organized movement by matrons, which obtained a strong support from a large part of the upper class. While these women massively crowded the streets of Rome a debate took place in the forum between Cato, from the conservative faction standing against the repeal of the lex Oppia, and Valerius, who supported such repeal.
\end{abstract}

Keywords: lex Oppia, roman matrons, woman's demands, gender studies, Antiquity, feminism. 


\section{INTRODUCCIÓN. LA SITUACIÓN DE LAS MUJERES EN LA REPÚBLICA ROMANA}

El objetivo de este trabajo es el estudio de los movimientos reivindicativos protagonizados por las mujeres en la Roma republicana del s. Il a.C. Dada la magnitud de este ámbito de estudio se ha decidido analizar en profundidad la manifestación de las matronas para la derogación de la ley Opia (195 a.C.). Se parte de la teoría de la desigualdad de género entre hombres y mujeres, aunque esta se dé, como en este caso, en una misma clase social, junto con los preceptos de la "historia de género", que pretende "la incorporación de nuevas temáticas, la crítica a los sistemas interpretativos tradicionales, y una lectura de las fuentes desde otros puntos de vista" (Mirón Pérez, 2010: 115).

La sociedad romana se fundamentaba en el sistema patriarcal, que establecía la subordinación de la mujer respecto al hombre. Dicho sistema "se sostenía sobre bases jurídicas, expresadas luego en la organización religiosa, política y económica" (Cid López, 2006: 27). Este entramado normativo y jurídico es también el motivo por el cual las conductas femeninas consideradas modélicas por el pensamiento patriarcal de la Antigüedad romana se han mantenido durante tanto tiempo.

A pesar de la situación de subordinación generalizada de las mujeres, en la República no faltan mujeres poderosas, como Clodia o Sulpicia ${ }^{1}$. Un avance importante en la situación de las mujeres se deriva de la generalización del matrimonio sine manu que permite que muchas permanezcan legalmente bajo la tutela del padre ${ }^{2}$ y que, después de su muerte, queden titulares de un patrimonio, lo que les permite mayor libertad incluso casadas (Rodríguez López, 2018: 192).

También es relevante para las mujeres de la República el contexto imperialista romano de los s. III y II a.C., ya que, con la ausencia de los padres que las tutelan ${ }^{3}$, ciertas matronas romanas tienen la posibilidad de asumir en cierto modo el rol del pater familias. En efecto, "podemos suponer que las mujeres fueron liberadas de muchas limitaciones, porque no había hombres parientes alrededor para hacerlas cumplir" (Culham, 1982: 789). Además, la riqueza de las mujeres se incrementa a causa de la elevada mortalidad masculina, ya que en algunos casos las convierte en las únicas herederas de los bienes familiares (Cid López, 2006: 31). Asimismo, la llegada de esclavos con los botines de guerra permite que las matronas de las familias aristocráticas puedan relegar sus tareas domésticas y dedicar su tiempo libre a cultivarse. La mejora de su situación económica y el acceso al conocimiento y la cultura supone un incremento del poder de estas mujeres que les posibilita también participar en cierta medida en la vida pública y política. Todo ello genera una fuerte reacción

\footnotetext{
1 Para más información sobre estas mujeres: Cantarella (1997).

2 La tutela es llevada a cabo normalmente por el pater familias y en muchos casos posteriormente por el marido. El tutor se encarga de controlar y proteger a "los que son considerados incapaces de entender o de querer, para impedir la comisión de actos perjudiciales" (Cantarella, 1991: 209). En el caso de los hombres, estos solo tienen tutor hasta que cumplen catorce años, mientras que la mujer es considerada incapaz toda su vida y por tanto tiene tutela perpetua.

3 El imperialismo romano de los s. III y II a.C. supuso un estado de guerra constante para Roma. Eso provocó la necesidad de continuas incorporaciones al ejército, por lo que muchos hombres tuvieron que dejar sus casas para participar en las campañas imperialistas.
}

del sistema patriarcal, que aprovecha ciertas circunstancias para promulgar leyes que pretenden restringir a las mujeres el pleno disfrute de sus bienes.

\section{MÉTODO}

Este trabajo parte de una investigación más amplia que pretendía rastrear las posibles reivindicaciones femeninas en la antigua Roma. Para ello se realizó una búsqueda de algunos términos como feminae (mujeres), matrona (-ae) (matrona, -as), uxor (-es) (esposa, -as), entre otros ${ }^{4}$, en la base de textos latinos Brepolis. Entre los resultados se identificaron un par de casos enmarcados en la República, y uno de ellos, el de la manifestación de las matronas para la derogación de la ley Opia, es el que se ha seleccionado para este ensayo en concreto. Para ello, se ha aplicado un análisis con perspectiva de género de las fuentes clásicas que hablan de este suceso, junto con una revisión de la bibliografía actual.

Se conservan diferentes fuentes clásicas que ofrecen información sobre la ley Opia. Algunos autores simplemente mencionan la existencia de la ley, como Paulo Orosio (Hist. 4, 20,14 ) y Plutarco (Quaest. Rom. 5, 56). Por otro lado, Plauto refleja satíricamente las circunstancias sociales previas a su promulgación (Aul. 498-536; Epid. 222-236; Poen. 210 ss.) ${ }^{5}$. Los que hablan más extensamente de la manifestación de las matronas y la derogación de la ley son Zonaras $(9,17,1-4)$, Valerio Máximo (9, 1, 3), Tácito (Ann. 3, 33-34), y Tito Livio, cuya narración es la más pormenorizada $(34,1-8)$.

Los problemas que presentan estos testimonios son, en primer lugar, que no se pueden contrastar con ningún documento original, ya que están escritos en un momento posterior al suceso analizado. En segundo lugar, que todos ellos están escritos por hombres de la élite, con el sesgo que esto implica.

\section{DISCUSIÓN}

El suceso que se estudia es el de la manifestación de las matronas romanas en favor de la derogación de la ley Opia, probablemente "la primera manifestación femenina de la Antigüedad" (García Jurado, 2011: 172) y "la más sorprendente manifestación del poder de las mujeres en toda la historia romana" (Bauman, 1992: 31). Dicha manifestación tiene lugar en la República, en el año 195 a.C., en un momento en el que, aunque la situación de las mujeres romanas de la élite ha mejorado ligeramente con respecto a la Monarquía y principios de la República, la presencia femenina en el ámbito público "se refleja en una imagen casi siempre criticable, porque deriva de un comportamiento que no se adecua con la moral tradicional" (Torrego, 2011: 290).

Parece que la ley Opia imponía restricciones severas al uso de los adornos por parte de las mujeres (Bauman, 1992: 31). Asimismo, la ley establecía que los ciudadanos varones tenían que contribuir con oro y plata al tesoro, una de cuyas fuentes eran las joyas y el dinero de sus esposas, junto con los objetos de la casa (MacLachlan, 2013: 58). Sin embargo,

\footnotetext{
4 Mulier (-eris) (mujer, -es), muliebris (adj. femenino), virgo (virgen), coniux (cónyuge), soror (-es) (hermana, -as), filia (-ae) (hija, -as), mater, -matres (madre, -es).

5 Para más información consultar García Jurado (1992) y (1993).
} 
los autores antiguos que hablan de las restricciones de la ley Opia (Livio, Valerio Máximo y Zonaras) mencionan a las mujeres como las únicas afectadas por ella. Estos mismos autores parecen coincidir ${ }^{6}$ en que la ley prohibía a las mujeres tener ${ }^{7}$ más de media onza de oro, llevar vestimentas de colores o enjoyadas e ir en carruajes de caballos a menos de media milla de la ciudad si no era para un acto religioso.

$\mathrm{Si}$ bien Tito Livio menciona que no considera relevante la ley Opia por sí misma ${ }^{8}(34,1,1)$, "la cuestión de la abrogación de esta ley suscitó toda una convulsión en Roma" (García Jurado, 2011: 172). Tanto Zonaras como Livio refuerzan esta idea afirmando respectivamente que: "el pueblo difundía la opinión de si sería necesario abolir la ley"9 (Zonar. 9, 17, 1), y que "muchos nobles intervenían en el debate para hablar a favor o en contra"10 (Liv. 34, 1, 4).

\section{Los diferentes contextos de la promulgación y la derogación de la ley Opia}

La ley Opia es aprobada en el 215 a.C. a partir de la propuesta del tribuno de la plebe Gayo Opio. El principal motivo que se argumenta para la promulgación de la ley es que, en pleno curso de la segunda Guerra Púnica, después de la derrota de la batalla de Cannas, los romanos necesitan urgentemente recursos económicos, que deciden obtener de las riquezas y lujos recién adquiridos por muchas matronas romanas a las que hacían responsables del declive económico por su comportamiento moral. Además, parece que esta ley tiene el objetivo de frenar la creciente riqueza de ciertas mujeres y refleja una "fuerte intención de tratar de recuperar viejos valores como modo de luchar contra el advenimiento de una generación de mujeres ricas -e ingobernables-" (Kühne, 2013: 42). Por otro lado, otro de los motivos es que, con las restricciones de la ley Opia, "se suavizarían las diferencias sociales en un intento de mantener compacta la estructura cívica en un momento de absoluta criticidad, también bajo el punto de vista del orden público" (Vettori, 2019: 58). Así pues, en este estudio interpretamos que no existe una única causa para la promulgación de la ley, ya que, tras las derrotas de la segunda Guerra Púnica, es necesario conseguir nuevos recursos y evitar revueltas internas para mantener el orden público. Pero la ocasión se aprovecha también para limitar los bienes y libertades recién adquiridos por algunas matronas y frenar así su empoderamiento.

Más tarde, después de la victoria romana sobre los cartagineses en el 201 a.C., se produce una rápida

6 Esta información se encuentra en Liv. 34, 1, 3; Val. Max. 9, 1, 3; Zonar. 9, $17,1$.

7 Hay un debate entre los investigadores sobre la interpretación de "tener" (habere). Algunos de ellos defienden que se tiene que traducir por "Ilevar", en el sentido de llevar en público más de media onza de oro encima, en forma de joyas, como Rentschler y Dawe (2011), o Culham (1982); mientras que otros lo traducen como "tener" o "poseer", como Tamer (2007) o Vassiliades (2019), entre otros.

8 De hecho, el propio Livio no habla de la promulgación de la ley cuando habla de los sucesos de ese año, solo menciona la ley por las circunstancias extraordinarias que rodean su derogación.

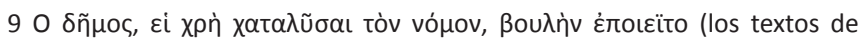
Zonaras se citan según la edición de Dindorf, 1870).

10 Ad suadendum dissuadendum que multi nobiles prodibant (los textos de Livio se citan según la edición de Briscoe, 1991). recuperación económica ${ }^{11}$. En estas circunstancias, los ciudadanos varones pueden volver a disfrutar libremente de sus bienes, mientras que las restricciones impuestas a las mujeres por la ley Opia siguen vigentes.

Veinte años después de la promulgación de la ley Opia, en el 195 a.C., los tribunos de la plebe Marco Fundanio y Lucio Valerio presentan una propuesta de derogación de la ley. Las matronas respaldan dicha propuesta "como las sufragistas de principios del s. XVIII manifestándose públicamente en las calles al mismo tiempo del debate" (Balsdon, 1962: 33). Los testimonios conservados informan de que las matronas ocupan las calles y los accesos al foro para persuadir a los hombres que participan en la votación para que apoyen la derogación de la ley. Por su parte, Zonaras menciona que incluso llegan a entrar en la asamblea $(9,17,4)$, mientras que Valerio Máximo únicamente afirma que las matronas rodearon la casa de los Brutos antes de la votación $(9,1,3)$, ya que estos habían amenazado con impedir la derogación de la ley (Liv. 34, 1, 4). En resumen, en palabras de Livio y Valerio Máximo, las matronas "se atreven"12 (Liv. 34, 1, 6; Val. Max. 9, $1,3)$. Se atreven a salir del ámbito privado y ocupar el público exigiendo a los hombres la derogación de la ley. Por ello, la actuación de las matronas "resultó un inadmisible exceso a los ojos de los romanos conservadores, que lo sentían como una profanación de los espacios de la vida pública reservados a los hombres" (Kühne, 2013: 48).

Cabe reflexionar brevemente sobre la actuación de las matronas en este episodio, ya que muestra "la realidad romana de la capacidad de las mujeres a la hora de oponerse a una medida determinada frente a lo que sí podían hacer los hombres" (Valmaña Ochaíta, 2017: 388). Es decir, los ciudadanos varones romanos tienen representación en los órganos de decisión de la ciudad y cuentan con instrumentos legales que pueden utilizar para expresar su opinión sobre determinados asuntos, e incluso intentar cambiar determinadas leyes, como ocurre en este caso. Sin embargo, las mujeres carecen de representación política y de medios legales para presentar sus propuestas, por lo que la única manera que tienen de expresar sus intereses o su posición respecto a ciertos asuntos es mediante la presión ejercida en la calle.

\section{El debate: discurso de Catón contra la derogación de la ley Opia}

El debate sobre la derogación de la ley Opia es iniciado por Catón ${ }^{13}$, que representa a los ciudadanos varones que

\footnotetext{
11 En palabras de Valerio Máximo, "el final de la segunda guerra púnica y la derrota del rey Filipo de Macedonia trajeron a nuestra ciudad el alivio de una vida más disipada" $(9,1,3)$. Urbi autem nostrae secundi Punici belli finis et Philippus Macedoniae rex deuictus licentioris uitae fiduciam dedit (edición de Kempf, 1888). Por su parte, Tácito afirma que "la ciudad ya no estaba, como antaño, asediada por guerras ni le eran hostiles las provincias" (3, 34, 2). Neque enim, ut olim, obsideri urbem bellis aut provincias hostiles esse (edición de Heubner, 1994).

12 Audebant; ausae.

13 Se podría interpretar que los dos discursos que presenta Livio en su versión del debate por la derogación de la ley Opia podrían estar dirigidos a la audiencia del año 195 a. C., pero también, principalmente, a los lectores de Livio, que ya estarían informados por el propio autor en los libros anteriores de su obra del papel crucial de la luxuria en el declive de Roma (Vassiliades, 2019: 107).
} 
están a favor de la ley. Es Livio quien presenta una versión más extensa del discurso de Catón, aunque esta parece ser una visión personal del historiador, que "podría haber estado significativamente influido por las imágenes de las mujeres y la riqueza que circulaban en los días de Livio" (MacLachlan, 2013: 58). En este análisis se aprecia que, en su conjunto, el discurso de Catón que presentan tanto Livio como Zonaras resulta absolutamente conservador y misógino.

Catón comienza hablando de la libertad de los hombres y la rebelión de las mujeres. Se deduce de su planteamiento que la libertad del hombre depende en gran medida del sometimiento de las mujeres. Además, los ciudadanos representados por Catón piden el mantenimiento de una ley para controlar la apariencia de las mujeres de la élite en el ámbito público. Es muy llamativo que Catón hable en varias ocasiones a lo largo de su discurso de una lucha constante entre hombres y mujeres, en la cual estas liberadas les aterrorizan, reflejando un "sentimiento de inferioridad oculto ante lo que ellos sienten como la superioridad femenina" (Rodríguez López, 2018: 217). También resulta significativo que el orador se dirija de esta forma al resto de los ciudadanos: "ahora, nuestra libertad, vencida en casa por la insubordinación de la mujer, es manchada y pisoteada incluso aquí en el foro" ${ }^{14}$ (Liv. 34, 2, 1-2), ya que este comentario refleja el aumento del poder de las matronas que tiene lugar en la República, que desencadena un nuevo y mayor conflicto entre hombres y mujeres en el ámbito doméstico que comparten, y que en este caso se transfiere también al ámbito público. Asimismo, es destacable que Catón afirme que "ninguna ley es ventajosa para todos; lo único que se pretende es que sea útil a la mayoría"15 (Liv. 34, 3, 4-5), ya que esa "mayoría" a la que es útil la ley Opia es únicamente masculina.

Posteriormente, el orador recuerda a los ciudadanos su responsabilidad sobre la defensa de los intereses del Estado $(34,2,5)$, señalando que "una dejación de funciones en este sentido afectaría la República y llenaría de oprobio tanto a los ciudadanos, como a los propios magistrados" (Valmaña Ochaíta, 2017: 401). De nuevo, se estima relevante que hable de intereses del Estado, cuando realmente se refiere a los intereses exclusivos de los ciudadanos varones, que quieren mantener el poder y el sometimiento de las mujeres. De la misma manera, resulta significativo que Catón afirme que el objetivo de la manifestación de las matronas no es digno, porque es egoísta y no pretende el bien común, cuando él mismo defiende los intereses egoístas de los hombres para la pervivencia del poder patriarcal. Además, Catón acusa a los tribunos Valerio y Fundanio de instigar a las matronas a la sedición, a la par que descalifica a ambos tribunos y a sus seguidores por haber mostrado cierta solidaridad con las matronas al defender su causa y permitir que ocupen las calles (Liv. 34, 5-8).

En su discurso, Catón subraya implícitamente la necesaria separación de los ámbitos masculino-público y femenino-privado, y defiende que las mujeres no deberían preocuparse en ningún caso por las leyes que se aprueban o derogan en el ámbito público (Liv. 34, 2, 10). En efecto, el

14 Nunc domi uicta libertas nostra impotentia muliebri hic quoque in foro obteritur et calcatur.

15 Nulla lex satis commoda omnibus est: id modo quaeritur, si maiori parti et in summam prodest. modelo dual tradicional "sitúa el ámbito de actuación de las mujeres dentro de la casa, donde era su deber mantener el patrimonio familiar de su marido, cuidar de él en su ausencia y criar a los hijos" (Torrego, 2011: 289). Por ello, se observa la preocupación por parte del orador de que las matronas salgan del ámbito privado, no solo físicamente, sino que también comiencen a pensar en las leyes, en el Estado y, en este caso particular, también en el disfrute de sus bienes al igual que los ciudadanos varones de su misma clase social. Esta preocupación se debe sin duda a que Catón está convencido de la capacidad de las matronas de conquistar sus derechos y de llegar a subvertir el orden social. El orador continúa afirmando que la de la mujer es una "naturaleza indisciplinada", comparándola con un "animal indómito", hablando de su "desenfreno" y anhelo de "libertinaje"16. En contraste con estos adjetivos que pronuncia el Catón de Livio en su discurso, el Catón de Zonaras exige que las mujeres hagan gala de la "prudencia, el amor a su esposo y a sus hijos, la capacidad de persuasión, y la moderación con las leyes establecidas"17 $^{\prime 1}(9,17,2)$. Está claro que el Catón de ambos autores considera que las mujeres son "un peligro para los cimientos de la sociedad romana. La mujer cuando conquista su libertad, rompe los vínculos y se convierte nada menos que en 'una bestia feroz'” (Rodríguez López, 2018: 217). Es más, parece que Catón está convencido de que "el deseo de las mujeres no se parará en la igualdad, sino que acabará desembocando en la supremacía" (Cuena Boy, 2017: 170).

Otro de los argumentos del Catón de Livio es que, al prohibir a las mujeres de la élite ir con joyas o vestidos de colores, todas las mujeres se igualan y se pierde, al menos aparentemente, la distinción de clases $^{18}$ (Liv. 34, 4, 12-13). Sin embargo, consideramos relevante el hecho de que iguale a las mujeres únicamente en la apariencia de pobreza y en el sometimiento al hombre, de forma que se perpetúe el sistema patriarcal, y que en ningún momento piense en equipararlas con los ciudadanos varones en su libertad y posesión de bienes y poder, ni plantee eliminar la diferencia de clase entre los hombres. Además, Catón utiliza un argumento económico que se repite en numerosas ocasiones a lo largo de la historia, y es que, si la ley se derogara y las mujeres pudieran disponer libremente de sus bienes, esto se traduciría en una merma del patrimonio de los hombres y por tanto del de sus hijos varones (Liv. 34, 4, 18-19), ya que estos tendrían menos bienes que heredar. Según Zonaras, Catón afirma incluso que las mujeres no tienen que ser poseedoras más que de las armas, las victorias y los triunfos de los hombres $(9,17,2-3)$.

Por último, cabe mencionar que en el trasfondo del discurso se entiende que el peligro principal para Catón es que las matronas se impliquen en asuntos públicos, políticos y cuya decisión corresponde a los ciudadanos varones. También parece temer que esto pudiera sentar un precedente, como se evidencia en los siguientes fragmentos de su discurso: "Y yo en mi fuero interno no llego a establecer si es peor el

16 Todas estas comparaciones y adjetivos están presentes en Liv. 34, 2, 1314 (Impotenti naturae; indomito animali; licentiae; licentiam).

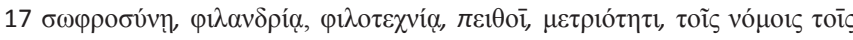
$\chi \varepsilon \mu \mu \dot{v} v 1 \varsigma$.

18 Esta aparente igualdad evitaría la competición entre las mujeres, que, según Catón, terminaría afectando negativamente a sus maridos (Liv. 34, 4, 15-17) 
hecho por sí mismo o por el precedente que sienta"19 (Liv. 34, $2,4)$; "se trata de que aboliendo una ley debilitéis todas las demás" ${ }^{20}$ (Liv. 34, 3, 4); "Ahora hacen peticiones en público a los maridos de otras y, lo que es más grave, solicitan el voto respecto a una ley"21 (Liv. 34, 4, 18).

\section{El debate: discurso de Valerio a favor de la derogación de la ley Opia}

En respuesta al discurso de Catón en contra de la derogación de la ley Opia, contesta Valerio con otro a favor. Consideramos que el aspecto clave del discurso del tribuno es que él mismo define la ley Opia como una ley promulgada contra las mujeres $(34,5,5)$. Valerio también señala que si se mantuviera la ley los ciudadanos varones estarán autorizados a utilizar prendas púrpuras ${ }^{22}$ y otros adornos mientras que, paradójicamente, sus mujeres no (Liv. 34, 7, 1-3). Además, defiende que las matronas ya han aparecido en público antes $^{23}$ en varias ocasiones, "y siempre por el bien común"24 (Liv. 34, 5, 8). Al respecto pone varios ejemplos, y afirma que en este caso la única diferencia es que solo están implicadas las matronas en la causa del movimiento, mientras que anteriormente se habían involucrado tanto mujeres como hombres.

Valerio Máximo destaca que la ley Opia era una medida de austeridad, promulgada en una situación de emergencia, y no una ley suntuaria ${ }^{25}$ (Vassiliades, 2019: 120). Así, retoma el discurso de Catón y acepta que no se deben derogar leyes "que han sido promulgadas para siempre"26, pero hace hincapié en que algunas leyes son "mortales y mudables con las propias circunstancias" 27 (Liv. 34, 6, 3-5). Mediante este argumento, interpretamos que el tribuno destaca, a su manera, la importancia del contexto socio-económico en la resolución de los cambiantes problemas sociales, que requieren también de una actualización normativa. Debido a eso, estimamos razonable y comprensible que las matronas exijan a los ciudadanos varones que les devuelvan el derecho de disfrutar de sus bienes y de los beneficios de la victoria frente a los cartagineses, ya que las circunstancias económicas han cambiado sustancialmente en una época de paz y esplendor económico.

Sobre el argumento de Catón respecto a la aparente pérdida de diferencia de clase entre las mujeres romanas, Valerio afirma que "todas ellas sufren y se sublevan cuando

19 Atque ego uix statuere apud animum meum possum utrum peior ipsa res an peiore exemplo agatur.

20 Hanc ut abrogetis, id est, ut unam tollendo legem ceteras infirmetis.

21 Nunc uolgo alienos uiros rogant et, quod maius est, legem et suffragia rogant.

22 "Los hombres utilizaremos la púrpura vistiendo la pretexta..., nuestros hijos vestirán togas ribeteadas de púrpura..." (Liv. 34, 7, 1-2). Purpura uiri utemur, praetextati...; liberi nostri praetextis purpura togis utentur....

23 Esto es importante, ya que Valerio reconoce en su discurso la participación histórica de las mujeres en asuntos públicos anteriormente, para la defensa de la ciudad o de sus habitantes, fundamentalmente en contextos bélicos. Ejemplos en Liv. 34, 5, 8-11.

24 Et quidem semper bono publico.

25 Las leyes suntuarias eran aquellas que tenían el objetivo de controlar los gastos para evitar los excesos y fueron promulgadas desde el s. III a.C. hasta el I d.C. (Tamer, 2007)

26 In aeternum latae sunt.

27 Mortales... et temporibus ipsis mutabiles. ven que a las mujeres de los aliados latinos se les permiten los ornatos que a ellas se les niegan" ${ }^{28}$ (Liv. 34, 7, 5). Este razonamiento se basa en la consideración romana de que es inadmisible que las mujeres de los latinos estén por encima de las de los romanos, porque ello implica el hecho impensable de que los hombres latinos puedan ser superiores a los propios romanos.

Parece que Valerio defiende la causa de las matronas, solidarizándose con ellas, pero en el trasfondo de su discurso se vislumbra claramente el pensamiento patriarcal sobre la inferioridad de la mujer. Es más, "el discurso de Valerio parece ser amistoso, pero es muy paternalista" (Hemelrijk, 1987: 219). Ese pensamiento queda patente también en la versión de Zonaras $^{29}$, en la cual el tribuno deja claro que el adorno es un asunto típicamente femenino y que, cuando se ven privadas de ello, las mujeres comienzan a pensar en política y en "asuntos masculinos". También podríamos interpretar que esta posición parece reflejar la consideración de la mujer como otro instrumento para la ostentación de la riqueza del hombre. En definitiva, se deduce que Valerio comparte con Catón la necesidad de mantener a las mujeres subordinadas y lejos de la vida pública y política, y que la única diferencia entre ambos es el medio con el que pretenden conseguirlo.

En cuanto a la relación entre hombres y mujeres, Valerio establece un paralelismo con la existente entre amo y esclavo, defendiendo que los ciudadanos varones no deberían indignarse "ante los ruegos de unas mujeres decentes, cuando los amos no se sienten molestos por las súplicas de sus esclavos" ${ }^{\prime 30}$ (Liv. $34,5,13$ ), si bien es cierto que también destaca que el control que tienen que tener los hombres sobre las mujeres debe ser distinto a una situación de esclavitud (Liv. 34, 7, 13). Ciertamente, este es un indicio de la convicción de Valerio de la subordinación de la mujer respecto al hombre, a pesar de las pequeñas libertades recién adquiridas por ellas. El tribuno tranquiliza también a los ciudadanos varones porque, si bien la derogación de la ley Opia podría significar un menor control sobre las mujeres, realmente seguirían sometidas y bajo tutela (Liv. 34, 7, 11-12). A su vez, recuerda la situación de debilidad de las mujeres, que las obliga a someterse a las decisiones de los hombres que las tutelan (Liv. 34, 7, 14-15), por lo que la derogación de la ley Opia no recaería en una pérdida real de poder para los ciudadanos varones en ningún aspecto. Finalmente, se puede ver que el trasfondo real del discurso de Valerio presenta una infravaloración de las mujeres típicamente patriarcal, según la cual el tribuno considera que "ellas solo muestran esta unión por un sentimiento de protección, y no estima la amenaza catoniana sobre la capacidad de unión femenina"

28 At hercule uniuersis dolor et indignatio est, cum sociorum Latini nominis uxoribus uideant ea concessa ornamenta quae sibi adempta sint.

29 “Pero tú, Catón, si sufres por el adorno de las mujeres y quieres hacer algo filosófico y elevado, córtales el pelo, vístelas con túnicas cortas y $\sin$ mangas y, por Júpiter, ármalas también y móntalas a caballo, y aun si te parece mándalas a Hispania, de modo que entren aquí y participen con

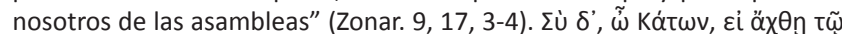

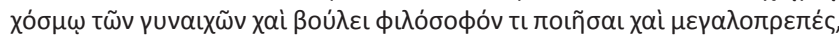

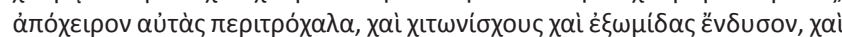

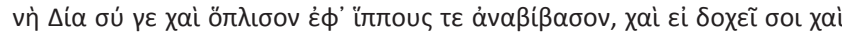

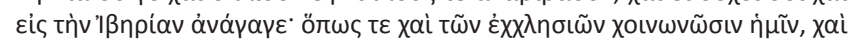

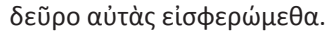

30 Si cum domini seruorum non fastidiant preces, nos rogari ab honestis feminis. 
(Rodríguez López, 2018: 200).

\section{Desenlace y secuela del conflicto}

Al día siguiente, después de la manifestación de las matronas y de los discursos en contra y a favor de la derogación de la ley, tiene lugar la votación. Es aprobada la propuesta de los tribunos Valerio y Fundanio, y se consigue la derogación de la ley, "fundamentalmente ante la contundente presión femenina en la calle, que decide no disolverse hasta que la medida sea abrogada" (Rodríguez López, 2018: 217). De todos los textos conservados, el desenlace más llamativo es el de Zonaras, que relata que tras la derogación de la ley las matronas "se colocaron adornos y salieron a ritmo de danza"31 $(9,17,4)$. Lo que interpretamos como una decisión de las matronas de celebrar la victoria por la consecución de un derecho reivindicado en el ámbito público.

\section{Discusión sobre las diferentes interpretaciones de la manifestación por la derogación de la ley Opia}

Esta extraordinaria manifestación protagonizada por un gran grupo de mujeres invadiendo el espacio público y exigiendo la devolución de sus derechos ha desencadenado numerosas interpretaciones.

Una propuesta interesante es la que defiende que el motivo del conflicto no es ni social ni de género, sino meramente político entre los dos hombres más importantes del momento, que defendían dos corrientes opuestas de pensamiento: Escipión y Catón. Basándose en esta idea, se sostiene que "Emilia, la mujer de Escipión, fue una de las instigadoras de la revocación, ella se habría asociado a una maniobra política que fue mucho más allá de la ocasión inmediata" (Bauman, 1994: 33). También parece que tras el conflicto de la derogación de la ley Opia "se esconde toda una serie de pujas políticas con cruzadas insinuaciones de desestabilización y de persecución entre ambos exponentes de los grupos dominantes" (Kühne, 2013, 51).

Asimismo, algunos investigadores defienden que la interpretación de este suceso como una reivindicación de género resulta imposible, ya que "las matronas solo intentaron aquí, puntualmente a través de una protesta pública influir en una decisión política y no pretendieron ni reivindicaron cambio político o social relevante alguno" (Casinos Mora, 2015: 244).

Por el contrario, la movilización de las matronas exigiendo el cambio de una ley que las afectaba exclusivamente a ellas podría ser considerada como activismo (Valmaña Ochaíta, 2017: 415). En la manifestación por la derogación de la ley Opia también hay "un claro síntoma de la creciente emancipación y autoafirmación de la mujer" (Gallardo Mediavilla y Sierra de Cózar, 1986: 301). Además, en esta manifestación las matronas no sirven a los dictados de la autoridad de los varones, poniendo de manifiesto su capacidad para tomar iniciativas (Cid López, 2010: 149). Así, esta última autora refuta la propuesta de Bauman y otorga la iniciativa y el protagonismo del suceso a las mujeres.

Sin embargo, a partir de esta investigación se deduce,

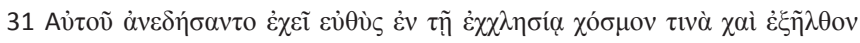

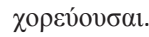

en primer lugar, que en este conflicto los motivos políticos no son los únicos, ya que hay un trasfondo social, económico y de género mucho más complejo. En segundo lugar, se juzga que un movimiento reivindicativo y organizado por las matronas en este contexto histórico y social es en sí mismo sumamente sorprendente y relevante, aún más si se tiene en cuenta que consigue tener éxito y permite que las matronas obtengan el derecho a disfrutar libremente de sus bienes al igual que los hombres de su grupo social. Es más, si la ley Opia hubiera afectado también al modo en el que los ciudadanos varones mostraban su riqueza, incluso en tiempos de recuperación económica, cabría pensar que las matronas no habrían llevado a cabo una protesta de tal magnitud. Se puede interpretar que las matronas romanas pudieron sentirse discriminadas por esta ley, ya que sentían que les privaba de decidir libremente sobre el uso de su riqueza, como sí podían hacer los ciudadanos varones. Hay que tener en cuenta que esa es la única manera que tienen las mujeres de afianzar su status, frente a las múltiples formas disponibles para los ciudadanos varones. Es evidente que esta es una lucha de género, aunque afecte solo a una clase social, ya que reivindica la derogación de una ley que discrimina a las mujeres de la élite con respecto a los hombres de su mismo grupo social. En efecto, las mujeres que participan en este movimiento son exclusivamente las más ricas de Roma, pero, sin embargo, se constituyen como un movimiento con identidad propia capaz de manifestar una oposición suficiente para generar reformas legislativas.

\section{CONCLUSIONES}

A pesar de que hay un cierto consenso social sobre el surgimiento de los movimientos sociales reivindicativos llevados a cabo por las mujeres a finales del s. XVIII, la investigación realizada muestra claramente que estas no han tenido un papel pasivo y sumiso a lo largo de la Historia, sino que ya en la antigua Roma hay sucesos que muestran que las mujeres salieron de la reclusión del ámbito doméstico y ocuparon el público con movimientos sociales reivindicativos para defender sus intereses. También cabe destacar la necesidad de una lectura crítica y con perspectiva de género de las fuentes clásicas que se han conservado, ya que esta es la forma de identificar qué hechos reales protagonizados por las mujeres se narran en las obras y superar así el sesgo de los autores. De esta forma, se podría hacer justicia histórica y dar voz a todas esas mujeres pioneras que lucharon por mejorar su situación y que fueron minusvaloradas por el relato histórico tradicional.

La ley Opia supone la privación de las mujeres no solo de la libre utilización de sus bienes, sino también de su propia imagen y su libertad de movimiento, a la vez que la imposición del recato y la discreción como modelo de conducta para la mujer de la élite. Por ello, es muy importante, no solo para la Historia en general, sino para la historia antigua y la historia del feminismo en particular, el hecho de que en el 195 a.C. las mujeres más ricas de la sociedad romana fueran capaces de organizarse para exigir que el derecho a utilizar y disfrutar sus bienes les fuera devuelto.

Comparando los dos discursos pronunciados en el conflicto por la derogación de la ley Opia, se interpreta claramente que tanto Catón como Valerio reflejan la opinión 
patriarcal imperante sobre la necesidad de mantener a las mujeres subordinadas y lejos de la vida pública y política, aunque defiendan diferentes formas de lograrlo. Asimismo, se considera que, aunque Catón resulte misógino, su preocupación se debe al convencimiento de que las mujeres son capaces de organizarse para reivindicar ciertos asuntos, cambiar las leyes, como muestra este episodio, y subvertir el orden social debilitando el sistema patriarcal. Sin embargo, interpretamos que Valerio, que es el que apoya la posición de las mujeres, considera que son demasiado débiles como para organizarse en un movimiento capaz de constituir un peligro para el sistema patriarcal ni para los valores morales y sociales en los que se sustenta.

Finalmente, en cuanto a las diversas interpretaciones que ha suscitado el conflicto, resulta decepcionante que todas las investigaciones se centren en los adornos y el lujo y reproduzcan la trivialidad con la que se trata la causa de la reivindicación en los textos clásicos, por ser estos escritos por hombres conservadores. Dichos investigadores no han considerado el empoderamiento que otorgaba a las matronas romanas el libre uso de sus riquezas y la libre decisión sobre la propia imagen en público, además de la libre elección de los medios de desplazamiento. Por otro lado, se puede concluir que, si bien la disputa política entre los hombres es importante, no es el elemento principal. Las protagonistas de este episodio son las mujeres, que demuestran su capacidad de salir del ámbito doméstico y tomar decisiones respecto a determinados temas en una protesta organizada y multitudinaria capaz de conseguir el apoyo de buena parte de la sociedad poderosa, alineando coyunturalmente sus intereses, aunque sus motivos fueran distintos. Además, se aprecia en sus reivindicaciones un anhelo de igualdad con los ciudadanos varones tanto en la capacidad de decisión sobre el libre uso de sus bienes como en la posibilidad de opinar sobre los asuntos públicos, como son la promulgación o la derogación de una ley, y de participar en el ámbito público y político junto a ellos.

\section{AGRADECIMIENTOS}

Me gustaría expresar mi agradecimiento a Rosario López Gregoris por su apoyo y estímulo en la realización de mi investigación, y por la revisión de este artículo.

\section{REFERENCIAS}

\section{Ediciones y traducciones}

Briscoe, John. 1991. Titi Livi. Ab Urbe Condita. Libri XXXI-XL. Sttutgart: Teubner.

Dindorf, Ludwig August. 1870. Ioannis Zonarae. Epitome Historiarum. Vol. I. Leipzig: Teubner.

Heubner, Heinrich. 1994. P. Cornelii Taciti. Libri qui supersunt. Tom.1. Ab Excessu divi Augusti. Sttutgart: Teubner.

Kempf, Carolus. 1966 [1888]. Factorum et dictorum memorabilium libri novem. Sttutgart: Teubner.

López Moreda, Santiago; Harto Trujillo, Mạ Luisa; Villalba Álvarez, Joaquín. 2003. Valerio Máximo, Hechos y dichos memorables, libros VII-IX. Epítomes, (introducción, traducción y notas). Madrid: Gredos.

Moralejo, José Luis. 1979. Cornelio Tácito, Anales, libros I-VI, (introducción, traducción y notas). Madrid: Gredos.

Plácido Suárez, Domingo. 2004. Dión Casio, Historia Romana, Libros I-XXXV (fragmentos), (introducción, traducción y notas). Madrid: Gredos.

Villar Vidal, José Antonio. 1993. Tito Livio, Historia de Roma desde su fundación, libros XXXI-XXXV, (traducción y notas). Madrid: Gredos.

\section{Fuentes secundarias}

Balsdon, John Percy Vyvian Dacre. 1962. Roman Women. Their History and Habits. Westport: Greenwood Press.

Bauman, Richard. 1994. Women and Politics in Ancient Rome. London: Routledge.

Cantarella, Eva. 1991. La calamidad ambigua. Madrid: Ediciones Clásicas.

Cantarella, Eva. 1997. Pasado próximo: mujeres romanas de Tácita a Sulpicia, Madrid: Cátedra.

Casinos Mora, Francisco Javier. 2015. La restricción del lujo en la Roma republicana: el lujo indumentario. Madrid: Dykinson.

Cid López, Rosa María. 2006. Prototipos femeninos en la Roma antigua: matronas y libertinas. En Mujeres en movimiento. Historia y Literatura, Rosa Sierra del Molino (Coord.), 27-56. Las Palmas de Gran Canaria: Universidad de las Palmas de Gran Canaria.

Cid López, Rosa María. 2010. Mujeres y actividades políticas en la República. Las matronas rebeldes y sus antecesoras en Roma antigua. En Mujeres en la antigüedad clásica. Género, poder y conflicto, Almudena Domínguez Arranz (Ed.), 125-152. Madrid: Sílex.

Cuena Boy, Francisco. 2017. Leges in aeternum latae y leges mortales: El debate sobre la derogación de la lex oppia según Tito Livio 34. 1-8. Ars Boni et Aequi 13(2): 157-189.

Culham, Phyllis. 1982. The 'Lex Oppia'. Latomus 41(4): 786793.

Gallardo Mediavilla, Carmen y Sierra de Cozar, Ángel. 1986. Tópicos sobre la mujer en la historia romana de Tito Livio. En La mujer en el mundo antiguo, Elisa Garrido (Ed.), 298-307. Madrid: Ediciones Universidad Autónoma de Madrid.

García Jurado, Francisco. 1992. La crítica al exceso ornamental femenino en la comedia latina a partir de los recursos léxicos relativos a la Lex Oppia. Minerva 6: 193-200.

García Jurado, Francisco. 1993. Las críticas misóginas a las matronas por medio de las meretrices en la comedia plautina. Cuadernos de Filología Clásica. Estudios latinos 4: 39-48.

García Jurado, Francisco. 2011. Matronas y meretrices en la comedia latina. Dos discursos en conflicto. En Ideas de mujer. Facetas de lo femenino en la Antigüedad, Rosario López Gregoris y Luis Unceta (Eds.), 317-341. Alicante: Publicaciones Universidad de Alicante.

Hemelrijk, Emily. 1987. Women's Demonstrations in Republican Rome. En Sexual Assimetry: Studies in Ancient Society, Josine Block y Peter Mason (Eds.), 217-240. Amsterdam: J. C. Gieben.

Kühne, Viviana. 2013. La lex Oppia sumptuaria y el control sobre las mujeres. En Mulier. Algunas Historias $e$ Instituciones de Derecho Romano, Rosalía Rodríguez López y María José Bravo Bosch (Eds.), 37-52. Madrid: 
Dykinson.

MacLachlan, Bonnie. 2013. Women in Ancient Rome: A Sourcebook. London - New York: Bloomsbury.

Mirón Pérez, María Dolores. 2010. Mujeres y poder en la antigüedad clásica: historia y teoría feminista. Saldvie: Estudios de prehistoria y arqueología 10: 113-126.

Rentschler, Lucas y Dawe, Christopher. 2011. Lex Oppia: An Ancient Example of the Persistence of Emergency Powers. Laissez-Faire 34: 21-29.

Rodríguez López, Rosalía. 2018. La violencia contra las mujeres en la Antigua Roma. Madrid: Dykinson.

Tamer, Diler. 2007. Lex Oppia and the Sumptuariae Leges. Annales 39, no 56: 121-128.

Torrego, Esperanza. 2011. Querer mandar en Roma: historia de una seducción. En Ideas de mujer. Facetas de lo femenino en la Antigüedad, Rosario López Gregoris y Luis Unceta (Eds.), 287-315. Alicante: Publicaciones Universidad de Alicante.

Valmaña Ochaíta, Alicia. 2017. Sobre el pretendido activismo político femenino en la República romana. En No tan lejano. Una visión de la mujer romana a través de temas de actualidad, María José Bravo Bosch, Alicia Valmaña Ochaíta y Rosalía Rodríguez López (Eds.), 375-416. Valencia: Tirant lo Blanch.

Vassiliades, Georgios. 2019. The lex Oppia in Livy 34.1-7: Failed Persuasion and Decline. En The Ancient Art of Persuasion across Genres and Topics, Sophia Papaioannou, Andreas Serafim y Kyriakos Demetriou (Eds.), 104-123. Leiden: Brill.

Vettori, Giulia. 2019. Il lusso che non si poteva concedere alle donne. Matrone e disciplina suntuaria nella Roma d'età repubblicana. En Quaderni 8. II lusso e la sua disciplina. Aspetti economici e sociali della legislazione suntuaria tra antichità e medioevo, Laura Righi y Giulia Vettori (Eds.), 51-84. Trento: Università degli Studi di Trento. Dipartimento di Lettere e Filosofia. 